\title{
Correction to: Reduced microbial potential for the degradation of phenolic compounds in the rhizosphere of apple plantlets grown in soils affected by replant disease
}

\author{
Viviane Radl ${ }^{\text {** }}$, Jana Barbro Winkler², Susanne Kublik', Luhua Yang ${ }^{1}$, Traud Winkelmann ${ }^{3}$, Gisle Vestergaard ${ }^{1,4}$, \\ Peter Schröder ${ }^{1}$ and Michael Schloter ${ }^{1}$
}

\author{
Correction to: Environ Microbiome (2019) 14:8 \\ https://doi.org/10.1186/s40793-019-0346-2
}

Following publication of the original article [1], the authors advised that their article had published with an error in the title.

The title read "Reduced microbial potential for the degradation of phenolic compounds in the rhizosphere of apples seedlings grown in soils affected by replant disease".

While the correct title is "Reduced microbial potential for the degradation of phenolic compounds in the rhizosphere of apple plantlets grown in soils affected by replant disease".

That is, the title referred to 'seedlings' in place of 'plantlets', which was the incorrect term because clonal plantlets (from the apple rootstock M26) were used, not seedlings.

The title has since been corrected in the original article.

The authors apologize for any inconvenience caused.

\section{Author details}

'Research Unit Comparative Microbiome Analysis, Helmholtz Zentrum München, Munich, Germany. ${ }^{2}$ Research Unit Environmental Simulations, Helmholtz Zentrum München, Munich, Germany. ${ }^{3}$ Woody Plant and

Propagation Physiology Section, Institute of Horticultural Production Systems, Leibniz Universität Hannover, Hanover, Germany. ${ }^{4}$ Department of Health Technology, Section for Bioinformatics, Technical University of Denmark, Lyngby, Denmark.

The original article can be found online at https://doi.org/10.1186/s40793019-0346-2

* Correspondence: viviane.radl@helmholtz-muenchen.de

${ }^{1}$ Research Unit Comparative Microbiome Analysis, Helmholtz Zentrum

München, Munich, Germany

Full list of author information is available at the end of the article
Published online: 27 December 2019

\section{Reference}

1. Radl V, et al. Reduced microbial potential for the degradation of phenolic compounds in the rhizosphere of apple plantlets grown in soils affected by replant disease. Environ Microbiome. 2019;14:8. https://doi.org/10.1186/ s40793-019-0346-2.

(C) The Author(s). 2020 Open Access This article is distributed under the terms of the Creative Commons Attribution 4.0 International License (http://creativecommons.org/licenses/by/4.0/), which permits unrestricted use, distribution, and reproduction in any medium, provided you give appropriate credit to the original author(s) and the source, provide a link to the Creative Commons license, and indicate if changes were made. The Creative Commons Public Domain Dedication waiver (http://creativecommons.org/publicdomain/zero/1.0/) applies to the data made available in this article, unless otherwise stated. 